\title{
Research on the Preparation of the Environmental Friendly Pillared Bentonite and Its Catalytic Properties
}

\author{
Xuan Zhang ${ }^{1,2, a}$, Qian Wang ${ }^{2, b}$ and Honglei Jiang ${ }^{2, c}$ \\ ${ }^{1}$ State Key Laboratory of Pulp and Paper Engineering, South China University of Technology , \\ Guangzhou 510640, China \\ ${ }^{2}$ Key Lab of Pulp \& Paper Science and Technology of Education Ministry of China, Shandong \\ Polytechnic University, Jinan 250353, China \\ a ahongjn@126.com, b wangqiandream@126.com, ${ }^{\mathrm{C}}$ jhl2000@126.com
}

Keywords: Fe, Al-pillared bentonite; catalytic activity; neutral condition

\begin{abstract}
An investigate was carried out to evaluate the catalytic performance of a Fe, Al-pillared bentonite for heterogeneous photo-Fenton systems. The catalyst was prepared by a cation doping technique and X-ray diffiraction and infraed spectroscopy were used to characterize its properties. The results showed that the main format of $\mathrm{Fe}$ was amorphous $\mathrm{FeOOH}$. Some bands of infrared spectroscopy shifted to lower wave length, indicating Fe and Al has intercalated into the layers of the bentonite. The Fe, Al-pillared bentonite exhibited a high catalytic activity under neutral condition. Complete discoloration was achieved in less than $60 \mathrm{~min}$ and mineralization ratio reached $76.9 \%$ in $120 \mathrm{~min}$. The catalytic activity decreased as the $\mathrm{pH}$ increased and the initial concentration of Orange II increased.
\end{abstract}

\section{Introduction}

The catalytic abatement of toxic organic compounds in wastewters has been extensively studied in the last years[1]. The heterogeneous photo-Fenton system was widely used to emilinate these hazardous compounds because of its mild condition and entire oxidation to organic pollutants. Various heterogeneous Fe-containing systems have been evaluated as catalysts for the processes. However, many of these systems possessed certain disadvantages such as low activity, low stability and only suitable to acidic condition. Layered silicate clays intercalated by polymeric inorganic oxocations are perspective catalysts due to high stability, microporosity, larger surface area and existence of acid sites. Catalysts based on pillared interlayered clays have been actively investigated in the last years[2,3]. Various pillared agents and various pillaring processes have been studied to improve the catalytic properities.

In this paper, a kind of Fe, Al-pillared bentonite (Fe, Al-PILC) was synthesized by Fe, Al-pillaring solutions and was used as the catalyst in a heterogeneous photo-Fenton process. X-ray diffraction (XRD) and Infrared Spectroscopy (IR) were used to characterize its properties. Orange II was chosed as a model compound to study the influent factors on catalytic properties.

\section{Experimental}

Materials. The natural bentonite was obtained from a bed located in Xinyang, Henan Province. It had the chemical composition $\mathrm{SiO}_{2}: 62.44$ wt.\%, $\mathrm{Al}_{2} \mathrm{O}_{3}: 15.00$ wt.\%, $\mathrm{Fe}_{2} \mathrm{O}_{3}: 4.05$ wt.\%, $\mathrm{CaO}: 2.48$ wt. $\%, \mathrm{MgO}: 1.43$ wt.\%, $\mathrm{Na}_{2} \mathrm{O}: 0.09$ wt. $\%, \mathrm{~K}_{2} \mathrm{O}: 0.21$ wt. $\%, \mathrm{MnO}$ and $\mathrm{TiO}_{2}: 0.2 \%, \mathrm{H}_{2} \mathrm{O}: 14.1$ wt.\%. The Na-containing layered bentonite used for the preparation of the pillared samples was synthesized by the treatment with $0.1 \mathrm{M} \mathrm{NaF}$ at a ratio $10 \%(\mathrm{w} / \mathrm{t})$ between solid and liquid phase at $90^{\circ} \mathrm{C}$ for $2 \mathrm{~h}$. This bentonite was ground and sieved to obtain a fraction passing through 200 mesh screen.

Synthesis of pillared bentonite. The Fe, Al-PILC was prepared through the following steps. First, an aqueous dispersion of $\mathrm{Na}$-containing bentonite was prepared by adding $6 \mathrm{~g}$ bentonite to $100 \mathrm{ml}$ of $\mathrm{H}_{2} \mathrm{O}$ under vigorous stirring for $2 \mathrm{~h}$ at $60^{\circ} \mathrm{C}$. Second, the $\mathrm{Fe}, \mathrm{Al}$-pillaring solutions $(\mathrm{Fe} / \mathrm{Al}=9 / 1)$ were 
prepared from mixing $\mathrm{Fe}\left(\mathrm{NO}_{3}\right)_{3}$ and $\mathrm{Al}\left(\mathrm{NO}_{3}\right)_{3}$ with the following hydrolysis using $\mathrm{Na}_{2} \mathrm{CO}_{3}$ $(\mathrm{OH} /(\mathrm{Al}+\mathrm{Fe})=2.0)$ at room temperature and the mixture was stored for $24 \mathrm{~h}$. Third, the Fe,Al-pillaring solutions obtained from the second step were added dropwise into the dispersion of bentonite prepared in the first step under vigorous stirring at $60^{\circ} \mathrm{C}$. The suspension was stirred for $2 \mathrm{~h}$ following by aging for $24 \mathrm{~h}$. The intercalated clay was filtered by suction, washed with distilled water, dried in air at $105^{\circ} \mathrm{C}$ overnight. Finally, the dried solid was calcined at $350^{\circ} \mathrm{C}$ for $4 \mathrm{~h}$.

Catalysis tests. The model pollutant for the evaluation of pillared bentonite catalyst was an azo-dye orange II. The choice of the dye was due to the fact that it was widely used in the textile industry and was not biodegradable[4]. Thus, it was a suitable model pollutant. The photo-Fenton discoloration and minerlization of Orange II was carried out under the reaction conditions of illumination by a $1 \times 8 \mathrm{~W}$ UVC lamp and at an ambient temperature of $30^{\circ} \mathrm{C}$. The Orange II concentration in the solution was determined using a UV-vis instrucment, $\lambda=486 \mathrm{~nm}$. The evaluation of total organ carbon (TOC) was measured by a Shimadzu TOC analyzer. In addition, to monitor Fe leaching from the pillaring bentonite, the Fe ion concentration in the reaction solution as a function of time was determined by the method of o-Phenanthroline Spectrophotometry.

Characterization of Fe, AL- PILC. XRD powder diffraction measurement of Fe, Al-PILC was performed on a powder diffractometer(D8-ADVANCE ) equipped with a $\mathrm{Cu} \mathrm{K \alpha}(\lambda=1.5418 \AA)$ radiation. IR spectra were recorded on a Shimadzu FIIR Prestige- 21 in the $400-4000 \mathrm{~cm}^{-1}$ range.

\section{Results and Discussion}

Characterization of the Catalyst. The XRD pattern of the pillared bentonite was shown in Figure 1. The $2 \theta$ angle of the basal reflections was $5.7^{\circ}$ that corresponded to the layer distance 5.64 $\AA$. It pointed out the stabilization of oxide pillars due to the introduction of bulky cation into the interlayer spaces of clay that prevented its silicate layers from closing on heating. Two diffraction peaks at $2 \theta=32.0^{\circ}$ and $41.9^{\circ}$ were assigned to $\alpha-\mathrm{Fe}_{2} \mathrm{O}_{3}$, but the intensity of the two peaks was very low, indicating that after calcined at $350^{\circ} \mathrm{C}$ for $4 \mathrm{~h}$, the Fe element mainly consisted of amorphous $\mathrm{FeOOH}$ and a small amount of $\alpha-\mathrm{Fe}_{2} \mathrm{O}_{3}$.

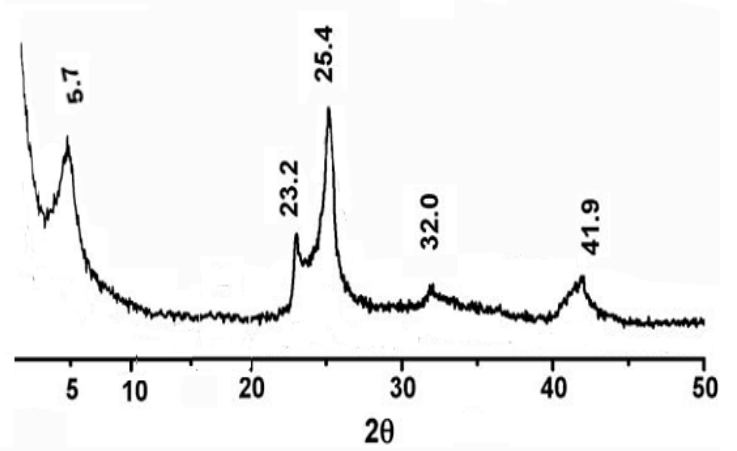

Fig.1 X-ray diffraction pattern of pillared bentonite

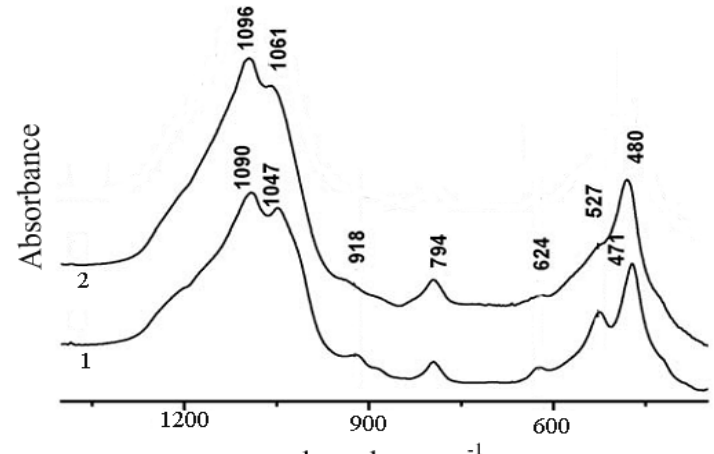

Fig.2 IR spectra of Na-clay(1) and $\mathrm{Fe}, \mathrm{Al}$-bentonite(2)

The IR spectra of Na-containing bentonite and Fe, Al-PILC samples were presented in Fig. 2. Bands at $1090 \mathrm{~cm}^{-1}$ and $1047 \mathrm{~cm}^{-1}$ assigned to stretching vibrations of silica-oxygen tetrahedrons $v_{\mathrm{as}}(\mathrm{Si}-\mathrm{O}-\mathrm{Si})$ and band at $471 \mathrm{~cm}^{-1}$ assigned to the bending $\mathrm{d}(\mathrm{Si}-\mathrm{O})$ and $\delta(\mathrm{Si}-\mathrm{O})$ and stretching $v(\mathrm{M}-\mathrm{O})$ vibrations were observed in IR spectra of $\mathrm{Na}$-containing bentonite. These bands appreciably shifted in IR-spectra of Fe, Al-pillared samples and the intensities of the bands at $1096 \mathrm{~cm}^{-1}, 624 \mathrm{~cm}^{-1}$ and $527 \mathrm{~cm}^{-1}$ were slightly lower for Fe, Al-pillared bentonite than that for Na-containing bentonite. The shift of bands at $1090 \mathrm{~cm}^{-1}, 1047 \mathrm{~cm}^{-1}$ and $471 \mathrm{~cm}^{-1}$ can be indirect evidence of the incorporation of Fe, Al-polycation into interlayers.

Discoloration and mineralization of Orange II at pH 6.0. Fig. 3 depicted the discoloration and mineralization of Orange II at neutral condition. Without any catalyst and $\mathrm{H}_{2} \mathrm{O}_{2}$ but only UV light (curve 1), the discoloration and mineralization of Orange II was negligible, indicating that Orange II could resist UV light. Without catalyst but with $\mathrm{H}_{2} \mathrm{O}_{2}$ and UV light (curve 3), the discoloration of 
Orange II was significant due to the oxidation of Orange II by OH radicals. With $1.0 \mathrm{~g} / \mathrm{L} \mathrm{Fe}, \mathrm{Al}-\mathrm{PILC}$ and $\mathrm{H}_{2} \mathrm{O}_{2}$, Orange II could also be degraded without the help of UV light, but the activity rate was less. With $1.0 \mathrm{~g} / \mathrm{L} \mathrm{Fe}$, Al-PILC, $\mathrm{H}_{2} \mathrm{O}_{2}$ and UV, the discoloration and mineralization were fastest. Complete discoloration could be achieved in less than $60 \mathrm{~min}$ and $76.9 \%$ mineralization could reach in $120 \mathrm{~min}$, indicating that the Fe, Al-PILC catalyst exhibited a good photocatalytic activity. It could be seen that the mineralization was more slower than discoloration, indicating than many long-lived colorless intermediates might be formed and many $\mathrm{OH}$ radicals decayed before they met the intermediates[5].
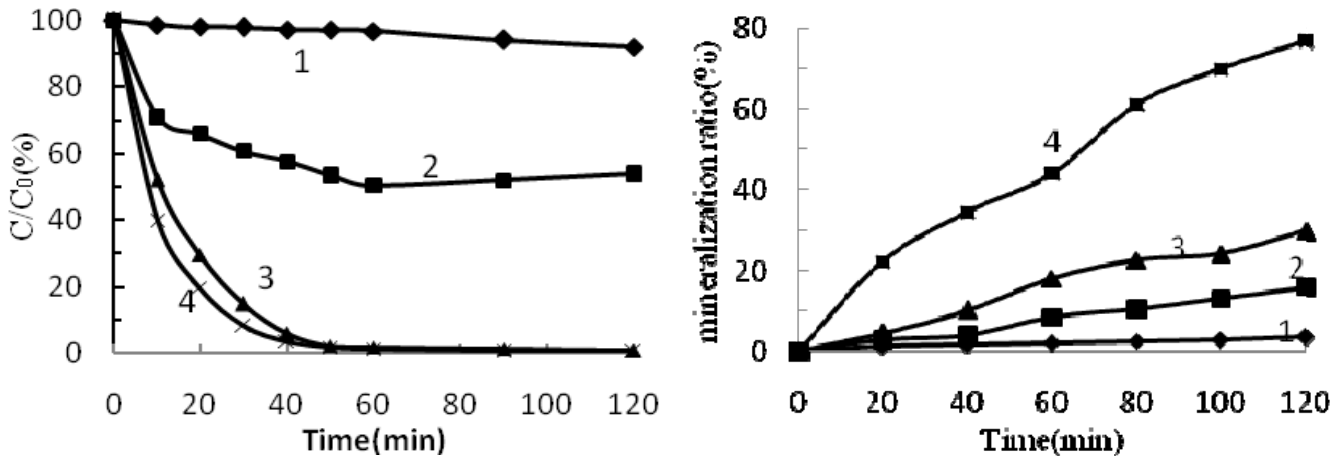

Fig. 3 Discoloration and mineralization of Organ II at pH 6.0: (1) dark $+8.4 \mathrm{mN} \mathrm{H}_{2} \mathrm{O}_{2}$, (2) dark $+8.4 \mathrm{mN} \mathrm{H}_{2} \mathrm{O}_{2}+$ $1 \mathrm{~g} / \mathrm{L} \mathrm{Fe}, \mathrm{Al}-\mathrm{PILC}$, (3) $\mathrm{UV}+8.4 \mathrm{mN} \mathrm{H}_{2} \mathrm{O}_{2}$, (4) $\mathrm{UV}+8.4 \mathrm{mN} \mathrm{H}_{2} \mathrm{O}_{2}+1 \mathrm{~g} / \mathrm{L} \mathrm{Fe}$, Al-PILC

Influence of the initial $\mathbf{p H}$. The optimum $\mathrm{pH}$ value for homogeneous Fenton process was around 3.0[6]. which corresponded to the maximum concentration of the activate $\mathrm{Fe}^{2+}$ species and to the lowest rate of $\mathrm{H}_{2} \mathrm{O}_{2}$ parasitic decomposition. By increasing the $\mathrm{pH}$, the precipitation of the insoluble ferric hydroxides took place and the decomposition of $\mathrm{H}_{2} \mathrm{O}_{2}$ became preponderant. This was the main limitation of the homogeneous.

The influence of the $\mathrm{pH}$ on the Orange II removal was studied using several solutions with determined $\mathrm{pH}$, without any modifications or control of the $\mathrm{pH}$ during the process. In Fig.4 the results obtained for the removal of Orange II as a function of the initial $\mathrm{pH}$ of the solution. It could be observed that that the photocatalytic activity of the Fe, Al-PILC decreased with increasing $\mathrm{pH}$ in initial solution. In $20 \mathrm{~min}$, the discoloration ratio could reach $90.7 \%$ at $\mathrm{pH} 3$, while $82.4 \%$ at $\mathrm{pH} 7$. According to the result of Fig. 3, complete discoloration could be achieved at the initial $\mathrm{pH} 6$. This characteristic made it possible to use Fe, Al-PILC as an effective heterogeneous photo-Fenton catalyst in a practical industrial application without preadjustment of the initial solution $\mathrm{pH}$ to a low solution $\mathrm{pH}$ such as 3.0, which could save a great amount of chemical and manpower. It was of particular significance in a practical industrial application of wastewater treatment.

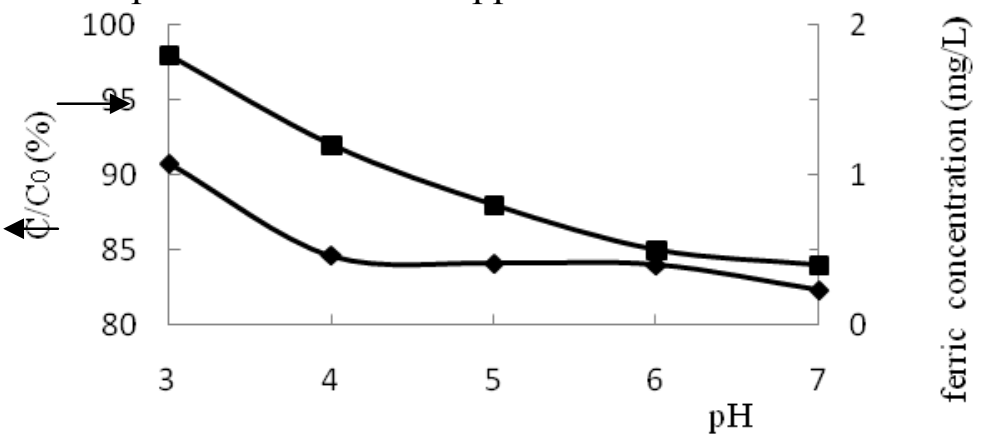

Fig. 4 Influence of the acidity of the solution on the discoloration and ferric concentration in the present of Fe, Al-PILC $(1 \mathrm{~g} / \mathrm{L})$

$\left.\left(\mathrm{TH}_{2} \mathrm{O}_{2}\right\rceil=8.4 \mathrm{mN}, 20 \mathrm{~min}\right)$

Compared with the Fe leaching behaviors under different initial solution $\mathrm{pH}$, the Fe leaching from the catalyst was depressed significantly from $1.8 \mathrm{mg} . \mathrm{L}^{-1}$ to $0.4 \mathrm{mg} . \mathrm{L}^{-1}$ as the $\mathrm{pH}$ increased. So at neutral condition only heterogeneous photo-Fenton accounted for the discoloration and mineralization and no significant homogeneous photo-Fenton reaction was observed due to the negligible Fe concentration. It also would help the catalyst to keep high photocatalytic activity.

Effect of concentration of initial Orange II. The effect of initial Orange II concentration on the discoloration of Orange II was studies and shown in Fig. 5. The lower the initial Orange II 
concentration, the shorter the reaction time needed to decolor completely. The absorbance of Orange II in the UV-vis region would made the UV light become less available for $\mathrm{H}_{2} \mathrm{O}_{2}$. The insufficiency of $\mathrm{H}_{2} \mathrm{O}_{2}$ for complete oxidation of $0.3 \mathrm{mM}$ Orange II was anthor reason. Both the reasons led to a significant decrease in the discoloration when the initial Orange II concentration increased.

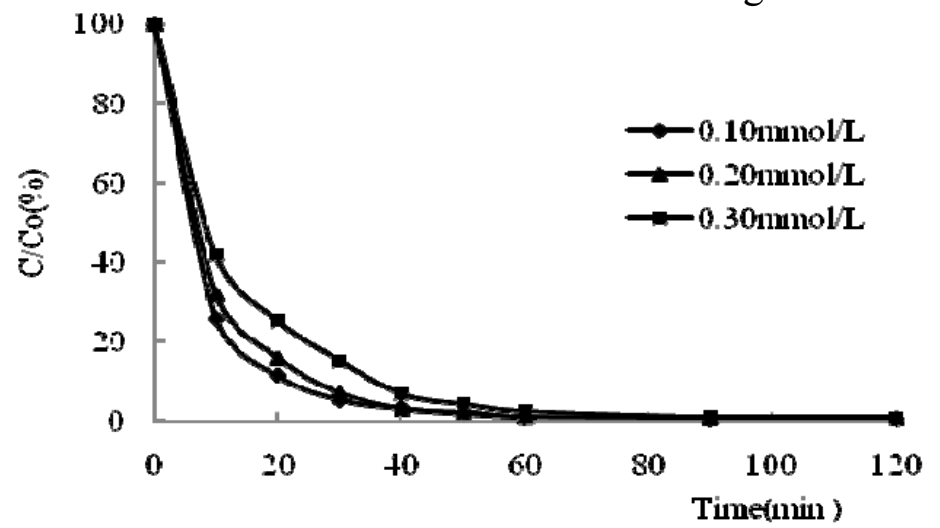

Fig. 5 Effect of initial Orange II concentration on the discoloration of Orange II

\section{Conclusion}

The Fe, Al-PILC has been synthesized by exchanging interlayer ions to polyoxocations. XRD and IR were used to characterize the product and its catalytic activity was studied. The Fe has entered into the layers of the bentonite and consisted of amorphous $\mathrm{FeOOH}$ mainly and a small amount of $\alpha-\mathrm{Fe}_{2} \mathrm{O}_{3}$. Complete discoloration could be achieved in less than $60 \mathrm{~min}$ and mineralization ratio reached $76.9 \%$ in $120 \mathrm{~min}$. The photocatalytic activity of Fe, Al-PILC decreased and the Fe leaching decreased significantly with increasing $\mathrm{pH}$ in initial solution. At the neutral condition the Fe, Al-PILC had a high heterogeneous catalytic activity. The absorbance of Orange II in the UV-vis region and the insufficiency of $\mathrm{H}_{2} \mathrm{O}_{2}$ for complete oxidation led to a decrease in the discoloration of Orange II when the initial concentration increased.

\section{Acknowledgement}

This work was financially supported by the Opening Foundation of State Key Laboratory of Pulp and Paper Engineering, Prior Special Study of 973 Program(Grant No.2011CB211705), National Science Foundation of China (Grant No.31070525), Natural Science Foundation of Shandong Province (Grant No.ZR2010CM065, ZR2011CM011).

\section{References}

[1] I. Oller, S. Malato, J.A. Sánchez-Pérez, M. I. Maldonado, W. Gernjak and L.A. Pérez-Estrada: Water Science and Technology Vol. 55 (2007), p. 229

[2] B. Iurascua, I. Siminiceanua, D. Vioneb, M.A. Vicente and A. Gil: Water Research Vol. 43 (2009), p. 1313

[3] X.H. Liu, R. Tang, Q. He, X. Liao and B. Shi: Journal of Hazardous Materials Vol. 174 (2009), p.687

[4] J. Femandez, J. Bandara, A. Lopez, P. Buffat and J. Kiwi: Langmuir Vol. 15 (1999), p.185

[5] J. Feng, X. Hu and P. Xue: Environmental Science Technonlgy Vol. 38 (2004), p.5773

[6] J. Feng, X. Hu and P. Xue: Environmental Science and Technology Vol. 38 (2004), p.269 